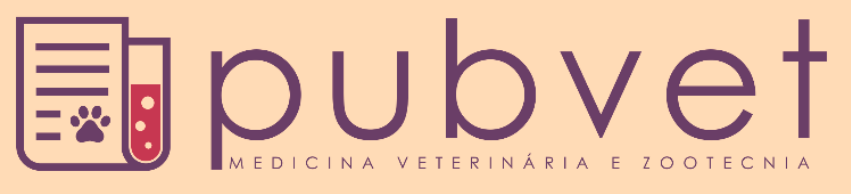

https://doi.org/10.31533/pubvet.v15n06a827.1-8

\title{
Conhecimento de tutores sobre a síndrome aérea dos cães braquicefálicos
}

\author{
Bianca Giraldelo Pitta Lopes $^{10}$, Thereza Christina de $\operatorname{Vasconcelos}^{20}$ \\ ${ }^{I}$ Dicente, medicina veterinária, Universidade do Grande Rio Professor José de Souza Herdy, Duque de Caxias, Rio de Janeiro, Brasil. \\ ${ }^{2}$ Docente e Coordenadora da Grande Rio Professor José de Souza Herdy, Departamento de Medicina Veterinária. Duque de Caxias -RJ Brasil. \\ *Autor para correspondência, E-mail: bianca_pitta@live.com
}

Resumo. A presente pesquisa teve como objetivo atestar o nível de conhecimento a respeito da síndrome das vias aéreas dos cães braquicefálicos que têm maior predisposição nas raças obtidas pelos tutores entrevistados. A síndrome das vias aéreas dos braquicefálicos se caracteriza pelo conjunto de anomalias do trato respiratório superior em animais braquicefálicos, onde podemos evidenciar estenose das narinas, prolongamento do palato mole e hipoplasia traqueal. Podendo ocorrer também alterações de cunho secundário como edema e espessamento do palato mole, disfunção da laríngea evoluindo para colapso laríngeo, edema de faringe e laringe, eversão dos sáculos laríngeos. Para realizar este estudo foram coletados os dados por questionários anônimo on line, realizados no formulário google de oitenta e três (83) tutores de cães braquicefálicos, realizado de janeiro até junho de 2020, para atestar seus conhecimentos sobre a existência dessa síndrome, sua gravidade, se há cura, se o animal possui a síndrome, e se o mesmo manifesta os sinais clínicos característicos de maneira recorrente. Segundo a pesquisa apenas $36,1 \%$ se informaram sobre a doença pelo seu médico veterinário de eleição, $34,9 \%$ afirmaram não saberem do que se trata, 18,1\% se informaram pela internet, $7,2 \%$ se informaram por um amigo ou familiar e 3,6\% pelas revistas ou jornais. Logo podemos concluir que apenas $39,7 \%$ dos tutores entrevistados se informaram sobre a doença através de fontes seguras. A maioria dos tutores já tinha ouvido falar a respeito da síndrome das vias aéreas dos cães braquicefálicos, mas não sabiam informar se seu animal possuía ou não a mesma, apesar de apresentarem um ou mais sinais clínicos recorrentes característicos. Foi evidenciado pelo presente estudo que o nível de escolaridade está diretamente relacionado à desinformação a respeito da síndrome, pela dificuldade que a falta de escolaridade proporciona dificultando o interesse em buscar fontes seguras de acesso à informação sobre a síndrome.

Palavras-chave: Braquicefálicos, cães, estenose, síndrome

\section{Assessment of tutors' knowledge about brachycephalic dogs aerial syndrome}

\begin{abstract}
The present research aimed to certify the level of knowledge about the airway syndrome of brachycephalic dogs, which is more predisposed in the breeds obtained by the interviewed tutors. The brachycephalic airways syndrome is characterized by the set of upper respiratory tract abnormalities in brachycephalic animals, where we can evidence stenosis of the nostrils, soft palate extension and tracheal hypoplasia. Secondary changes may also occur such as edema and thickening of the soft palate, laryngeal dysfunction evolving into laryngeal collapse, pharyngeal and laryngeal edema, and laryngeal sagging. To carried-out this study, data were collected through anonymous online questionnaires, realized on google form, of eighty-three (83) tutors of brachycephalic dogs, conducted from January to June 2020, to attest their knowledge about the existence of this syndrome, its severity, whether there is a cure, whether the animal has the syndrome, and whether it manifests the characteristic clinical signs in a recurrent manner. According to the survey
\end{abstract}


only $36.1 \%$ informed themselves about the disease by their veterinarian of choice, $34.9 \%$ said they did not know what it was, $18.1 \%$ informed themselves by internet, $7.2 \%$ informed themselves by a friend or family member and $3.6 \%$ by magazines or newspapers. Therefore, we can conclude that only $39.7 \%$ of the interviewed tutors informed themselves about the disease through reliable sources. Most tutors had already heard about Brachycephalic Dog Airways Syndrome, but they did not know if their animal had it or not, despite having one or more characteristic recurrent clinical signs. The present study has shown that the level of schooling is directly related to misinformation about the syndrome, due to the difficulty that the lack of schooling provides, making it difficult to look for safe sources of access to information about the syndrome.

Keywords: Brachycephalic, dogs, stenosis, syndrome

\section{Conocimiento de los tutores sobre el síndrome aéreo de los perros braquicefálicos}

Resumen. La presente investigación tuvo como objetivo certificar el nivel de conocimiento sobre el síndrome de la vía aérea de los perros braquicéfalos, que tiene una mayor predisposición en las razas obtenido por los tutores entrevistados. El síndrome de las vías respiratorias braquicefálicas se caracteriza por el conjunto de anomalías de las vías respiratorias superiores de los animales braquicefálicos, en las que podemos observar estenosis de las fosas nasales, extensión del paladar blando e hipoplasia traqueal. También pueden producirse cambios secundarios como edema y engrosamiento del paladar blando, disfunción laríngea que evoluciona hacia el colapso laríngeo, edema faríngeo y laríngeo, y hundimiento laríngeo. Para llevar a cabo este estudio, se recogieron datos mediante cuestionarios anónimos en línea, realizados en el formulario de Google, de ochenta y tres (83) tutores de perros braquicéfalos, realizados de enero a junio de 2020, para atestiguar su conocimiento de la existencia de este síndrome, su gravedad, si existe una cura, si el animal tiene el síndrome y si manifiesta los signos clínicos característicos de manera recurrente. Según la encuesta, sólo el 36,1\% se informó sobre la enfermedad a través del veterinario de su elección, el 34,9\% dijo no saber de qué se trata, el 18,1\% se informó a través de Internet, el 7,2\% se informó a través de un amigo o familiar y el 3,6\% a través de revistas o periódicos. Luego podemos concluir que sólo el $39,7 \%$ de los tutores entrevistados se informaron sobre la enfermedad a través de fuentes fiables. La mayoría de los tutores ya habían oído hablar del Síndrome de las Vías Respiratorias del Perro Braquicéfalo, pero no sabían si su animal lo tenía o no, a pesar de presentar uno o más signos clínicos característicos. En el presente estudio se demostró que el nivel de escolaridad está directamente relacionado con la desinformación sobre el síndrome, debido a la dificultad que supone la falta de escolaridad, lo que dificulta la búsqueda de fuentes seguras de acceso a la información sobre el síndrome.

Palabras clave: Braquicéfalo, estenosis, perros, síndrome

\section{Introdução}

Os cães apresentam três tipos de variações cranianas sendo divergentes em formato, tamanho e estrutura. As maiores variações em relação à estrutura são evidenciadas nos animais braquicefálicos (Stockard, 1941). Os cães braquicefálicos surgiram da criação seletiva intensiva, fazendo com que cada vez mais se tenha um tamanho reduzido do focinho e narina, prejudicando assim gravemente o seu funcionamento (Teichmann et al., 2012). Segundo Oechtering (2010), o gene responsável pelo ocasionar a redução da máxima não influencia os tecidos moles, levando ao prolongamento do palato mole.

A síndrome aérea dos cães braquicefálicos é um grupo de malformações anatômicas primárias como estenose de narinas, alongamento do palato mole, hipoplasia traqueal, e secundárias, edema de mucosa, eversão da saculação laríngea, que ocorre quando o animal exerce uma pressão negativa ao inspirar, causada pela malformação anatômica primária mencionada anteriormente, gerando uma inflamação dos tecidos moles presentes (Oechtering, 2010), colapso laríngeo e eversão de tonsilas, que acometem os braquicefálicos como Pug, Bulldog Inglês, Bulldog Francês, Boxer, ShihTzu, Lhasa Apso, e pode 
obstruir as vias aéreas superiores (Crivellenti \& Borin-Crivellenti, 2015). O trato respiratório superior é constituído por nariz, faringe, laringe e a traqueia, todo o ar que entra e sai dos pulmões passa por essas estruturas (Colville, 2011). Afeta qualquer sexo e mais comum em cães. Estes animais apresentam respiração difícil e ruidosa, intolerância ao exercício, cianose e sono inquieto (Carvalho et al., 2010).

Quando a malformação impede o fluxo de ar, os sinais clínicos serão compatíveis com o grau de obstrução. Esses sinais clínicos são aumentados por exercícios, excitação e temperaturas altas do ambiente. Logo, causando uma severa obstrução das vias aéreas podendo resultar em um edema pulmonar devido à redução da pressão intratorácica (Moraes et al., 2012).

O desígnio deste trabalho foi mensurar se os tutores de cães braquicefálicos têm conhecimento da síndrome, bem como sua importância para as raças afetadas.

\section{Material e métodos}

Para realizar este estudo foram coletados os dados via questionários anônimos on line, realizados no Formulário Google, de tutores, realizado de janeiro até junho de 2020, para atestar seus conhecimentos sobre a existência dessa síndrome, sua gravidade, se há uma possível cura, se o animal possui a síndrome, e se o mesmo manifesta os sinais clínicos característicos de maneira recorrente. $\mathrm{O}$ questionário utilizou como critério de inclusão de tutores de cães braquicefálicos e contemplou informações sobre o tutor, como idade, nível de escolaridade, gênero e renda familiar e questionamentos sobre a síndrome já o conhecimento da existência desta síndrome, sua gravidade, se o animal apresenta de maneira recorrente os e se há existência de cura. Já os dados sobre o animal era sua raça, se havia existência da síndrome no animal e se havia a presença dos sinais clínicos. Sendo assim foi traçando o perfil do tutor que adquire estas raças de animal (braquicefálico).

Os dados coletados através de questionário foram posteriormente analisados em Excel e apresentados através de gráficos estatísticos e figuras.

\section{Resultados e discussão}

No total, 83 tutores participaram da pesquisa e opinaram sobre a síndrome dos braquicefálicos. A maioria dos tutores entrevistados $(65,1 \%)$ demonstrou ter ciência da síndrome, mas 34,9\% dos entrevistados não sabiam se quer da existência da mesma (Gráfico 1).

A desinformação segundo os resultados obtidos na pesquisa está diretamente correlacionada ao nível de escolaridade, uma vez que 34,9\% dos tutores possuem baixo nível de formação acadêmica, como podemos visualizar no gráfico 2 .

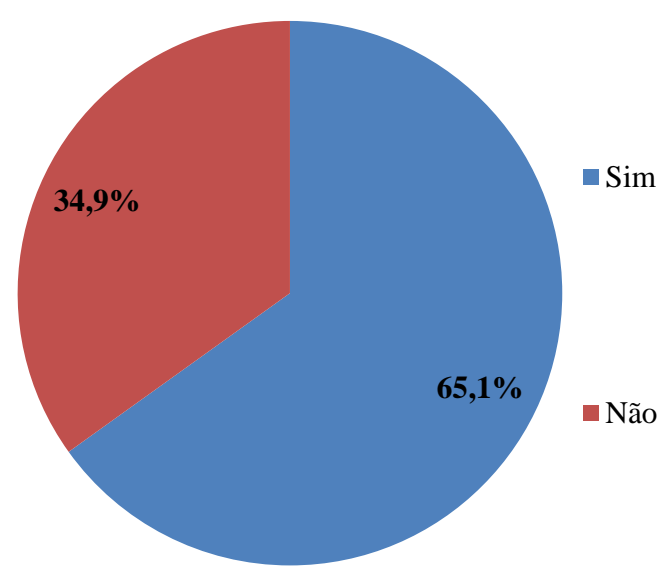

Gráfico 1. Percentual do gênero dos entrevistados sobre síndrome dos braquicefálicos por questionário fechado online entre janeiro e junho de $2020(n=83)$.

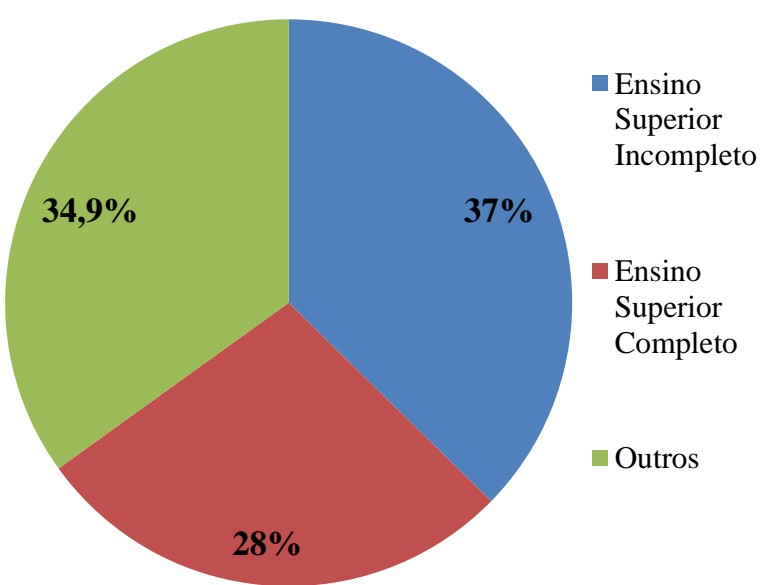

Gráfico 2. Percentual do grau de escolaridade (níveis médio e fundamental somados em "outros") dos entrevistados sobre síndrome dos braquicefálicos por questionário fechado online de janeiro a junho de $2020(n=83)$. 
A redução drástica da respiração, ocasionada pela estenose das narinas, prolongamento do palato mole e/ou hipoplasia traqueal, resulta na perda ou ineficiência de seu principal órgão termorregulador, ocasionando o aumento da temperatura interna corporal do animal podendo levá-lo ao colapso e ao óbito (Teichmann et al., 2012). Contudo, 38,6\% e 6,0\% dos tutores entrevistados acreditam que a síndrome talvez seja uma condição grave, e que não seja uma condição grave, respectivamente (Gráfico 3). E quando questionados se a síndrome braquicefálica poderia levar ao óbito 16,9\% dos entrevistados afirmaram que não e $83,1 \%$ que sim (Gráfico 4), uma contradição uma vez que apenas $55,4 \%$ dos entrevistados afirmaram que consideram a síndrome uma condição grave.

Quando perguntados sobre se o seu animal possuía o diagnóstico positivo para a síndrome braquicefálica (confirmado pelo um médico veterinário) apenas 13,3\% afirmaram que sim, 24,1\% afirmaram que não e 62,7\% não sabe se seu animal possui a mesma (Gráfico 5). Embora 89,2\% dos tutores relataram que seus animais possuíam de forma recorrente um ou mais sinais clínicos característicos da síndrome, sendo apenas $10,8 \%$ dos tutores que afirmaram que seu animal não apresenta nenhum dos sinais mencionados (Gráfico 6). O diagnóstico da síndrome se dá pelo histórico de roncos, dispneia, estridor, cianose e síncope. Exame físico e inspeção de narinas e palato mole com laringoscópio, em busca de malformações primárias como estenose de narinas e prolongamento do palato mole. Para melhor observação do palato, faringe e laringe, indica-se anestesia ou sedação (Crivellentin \& Borin-Crivelletin, 2015). Devem-se avaliar radiografias torácicas para detectar anormalidades cardíacas ou pulmonares adjacentes (Carvalho et al., 2010). No exame ecocardiográfico se evidencia hipertrofia concêntrica ventricular direita, aumento do átrio direito e insuficiência da tricúspide (Jericó et al., 2015).

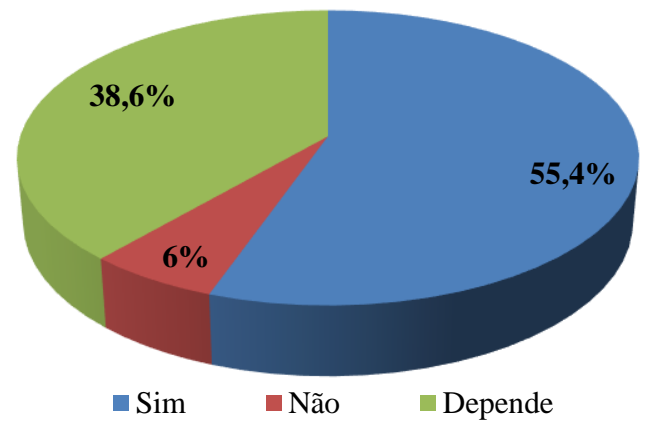

Gráfico 3. Percentual de entrevistados em questionário online que responderam se acham que Síndrome das Vias Aéreas dos Braquicefálicos é uma condição grave $(\mathrm{n}=83)$.

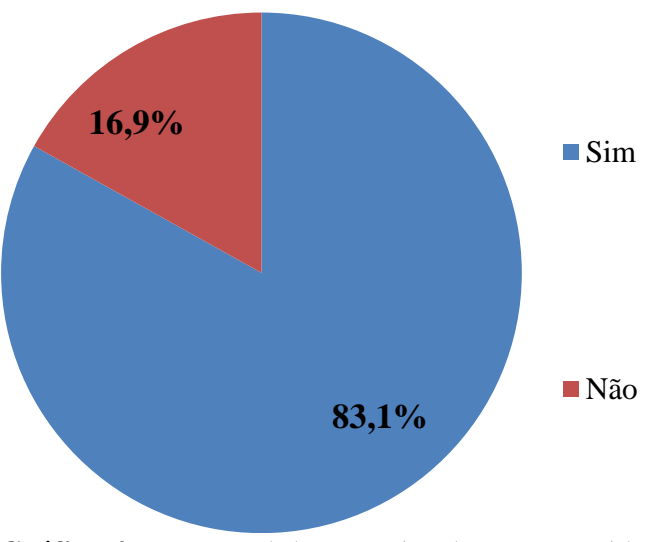

Gráfico 4. Percentual de entrevistados que consideram que a síndrome pode levar ao óbito a partir de um questionário online fechado de janeiro a junho de $2020(n=83)$.

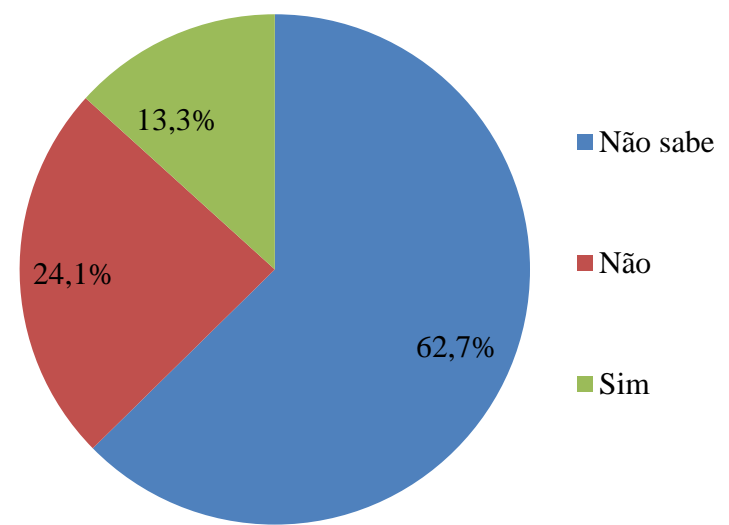

Gráfico 5. Percentual de entrevistados em questionário online fechado que afirmaram possuir a síndrome braquicefálica diagnosticada por um médico veterinário de janeiro a junho de $2020(\mathrm{n}=83)$.

Os sinais clínicos são em um modo geral consequência das malformações anatômicas, tanto primárias quanto secundárias, causadas pela síndrome. Podendo ocasionar importantes alterações secundárias, como no caso da estenose nasal que torna o fluxo aéreo para o interior da cavidade nasal 
restrito e torna-se necessário um esforço inspiratório maior, causando dispneia leve à intensa. A síndrome braquicefálica refere-se a uma combinação de estenose de narinas, alongamento de palato mole e eversão de sacos laringianos, comumente observadas nestas raças (Carvalho et al., 2010).

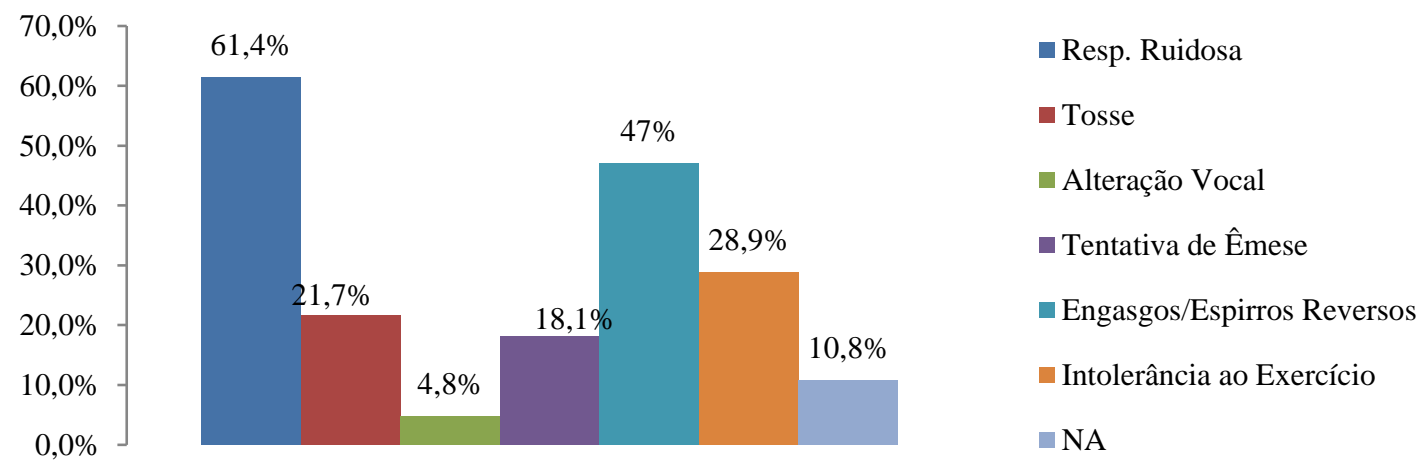

Gráfico 6. Percentual de entrevistados em questionário online sobre síndrome braquicefálica que responderam se o animal possui de maneira recorrente os sinais clínicos listados, de janeiro a junho de $2020(\mathrm{n}=83)$.

A traqueia é um tubo de tecido fibroso e musculatura lisa, que se mantém aberta por anéis cartilaginosos de hialina, revestido pelo mesmo epitélio ciliado presente nas passagens nasais. $\mathrm{Na}$ presença de colapso traqueal o espaço geralmente estreito entre as extremidades dos anéis em C são mais largas do que o normal. Quando o animal inala, a área alargada do músculo liso é aspirada para dentro do lúmen e bloqueia parcialmente a traqueia (Colville, 2011). O colapso traqueal possui uma classificação de acordo com o grau de comprometimento dos anéis cartilaginosos (Tangner \& Hobson, 1982).
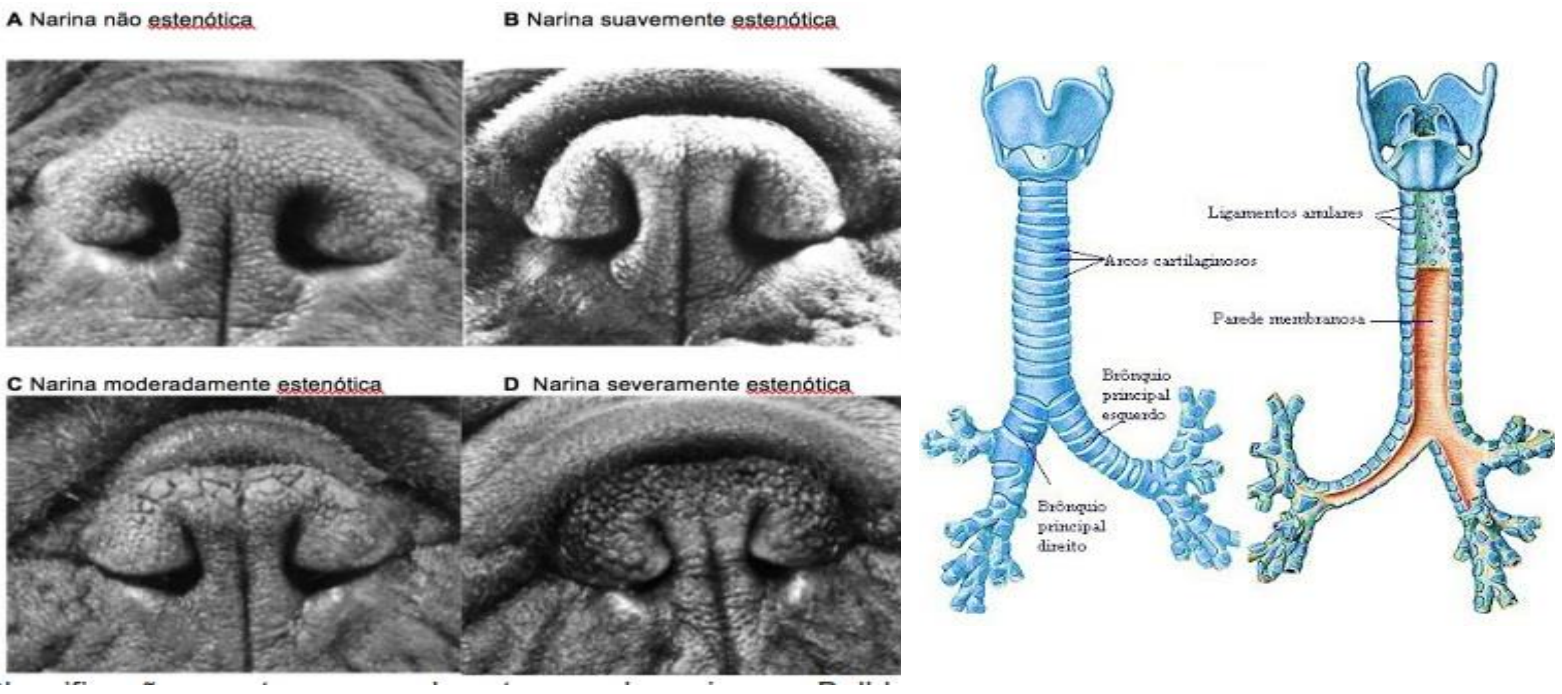

Figura 1. Grau de classificação de estenose de narina em buldogues franceses (Liu et al., 2016).

Figura 2. Ilustração da anatomia traqueal (Almeida, 2012)

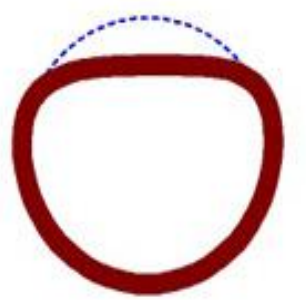

$25 \%$

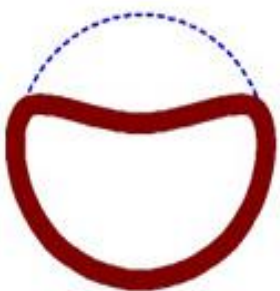

$50 \%$

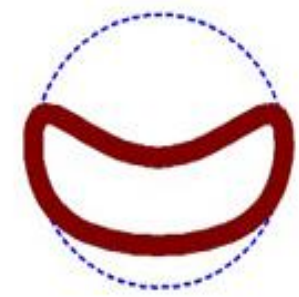

$75 \%$

Grad I

Grad II

Grad III

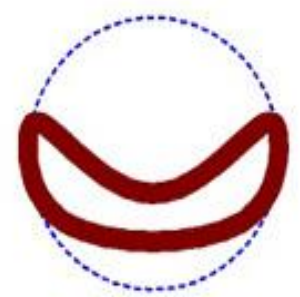

fast vollständig

Grad IV

Figura 3. Grau de comprometimento em colapso traqueal (Tangner \& Hobson, 1982) 
A ronqueira é a paralisia dos músculos que contraem a cartilagem aritenóide e as pregas vocais em uma lateral da laringe. O resultado é que a prega vocal afetada vibra com a passagem do ar, quando o animal respira. Normalmente isso não é um problema, quando o animal está em repouso, porém quando a respiração está ofegante e o animal está praticando exercícios, a prega vocal paralisa obstruindo parcialmente a glote no momento da inalação, dificultando a passagem do ar. A falta de ar provoca cansaço (esse fenômeno é conhecido como intolerância ao exercício) (Colville, 2011).

Há alterações secundárias, como consequência à síndrome, pode ocorrer dilatação gástrica e esofágica, flatulência, distúrbios na deglutição, êmese e regurgitação, hipertensão pulmonar, gastropatia hipertrófica e termorregulação comprometida (Jericó et al., 2015).

E $41 \%$ dos tutores de cães braquicefálicos afirmaram que em alguns casos a síndrome possui cura, e $31 \%$ afirmaram que sim e $28 \%$ negaram que haja uma cura (Gráfico 7).

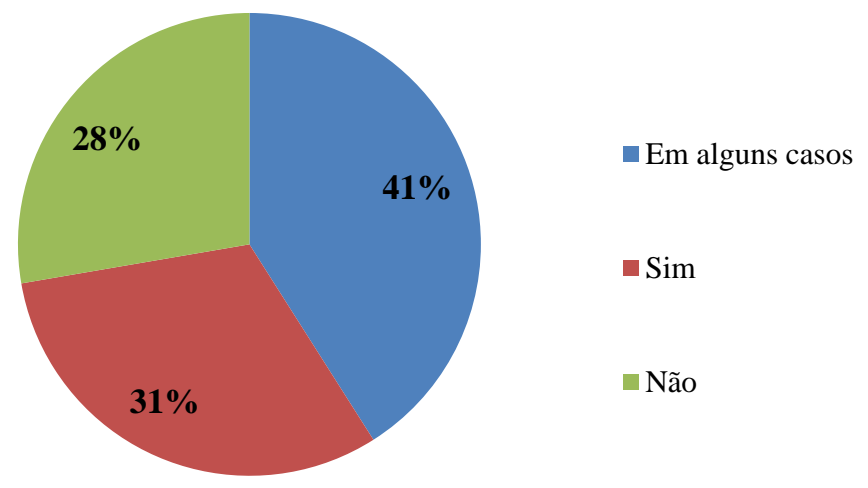

Gráfico 7. Percentual de entrevistados em questionário online fechado sobre síndrome braquicefálica que responderam se acreditam que a mesma possui cura, janeiro a junho de $2020(n=83)$.

O protocolo de tratamento é feito diante de um procedimento conservador clínico sendo utilizado oxigenoterapia, repouso, controle de temperatura, anti-inflamatórios esteroidais (como prednisona 0,5$1 \mathrm{mg} / \mathrm{kg}$ IV, no caso de cirurgia), vasodilatadores, caso haja hipertensão pulmonar secundária. E o tratamento cirúrgico onde há a correção das malformações anatômicas, como rinoplastia para correção da estenose de narinas, ressecção do excesso de palato mole e amputação dos sáculos laríngeos evertidos. No caso de colapso laríngeo, indica-se traqueostomia previamente à cirurgia (Crivellentin \& Borin-Crivelletin, 2015).

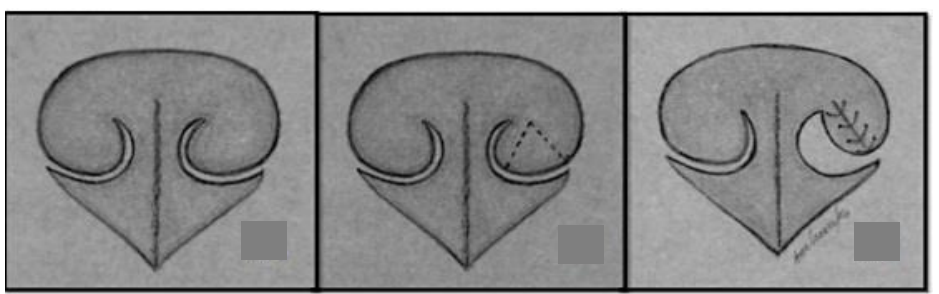

Figura 4. Ilustração da técnica utilizada na rinoplastia para ressecção em cunha da narina (Mendes Junior et al., 2019).
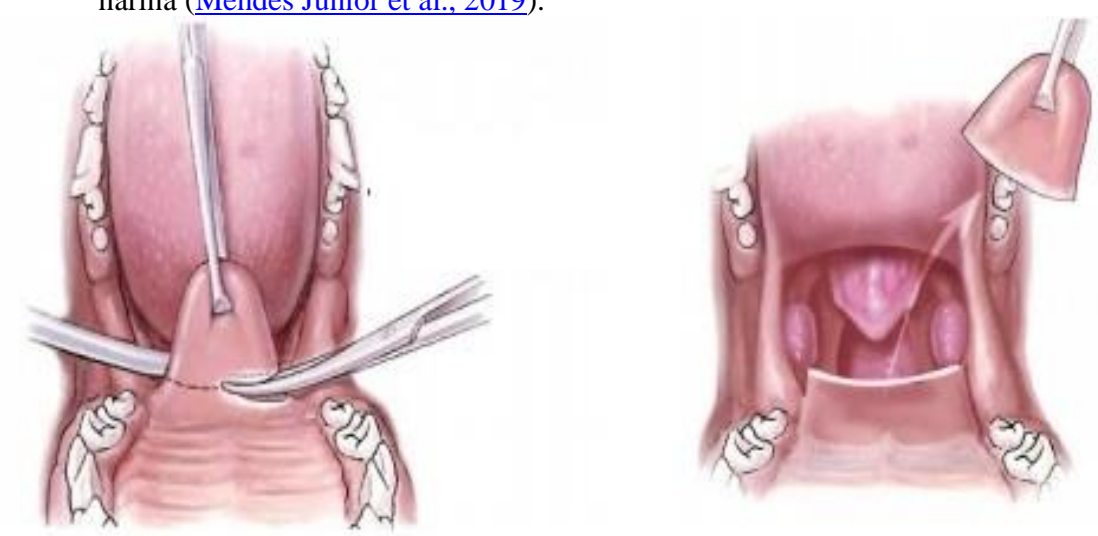

Figura 5. Ressecção do excesso de palato mole (Rawlings). 
Na pesquisa $80 \%$ do público (tutores) era feminino e 18,1\% masculino, sendo 1,2\% não mencionaram seu gênero (Gráfico 8). E a maioria dos entrevistados possuía entre 18 e 24 anos de idade (41\%) (Gráfico 9).

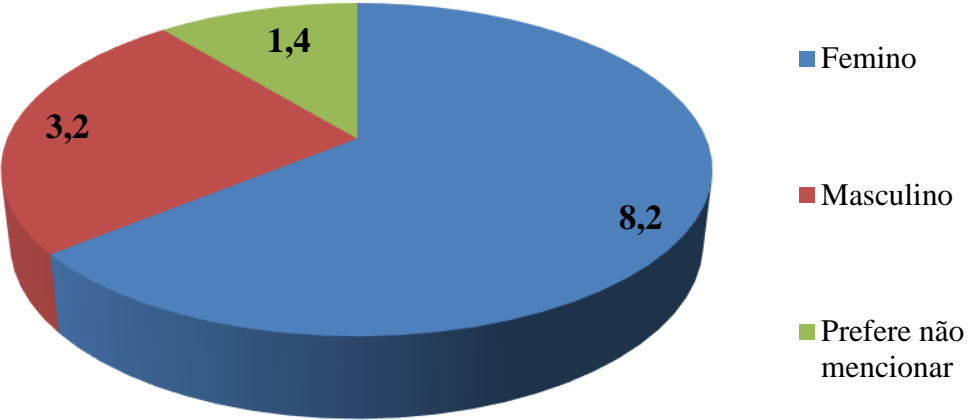

Gráfico 8. Percentual do gênero dos entrevistados sobre síndrome dos braquicefálicos por questionário fechado online entre janeiro e junho de 2020. $(n=83)$.

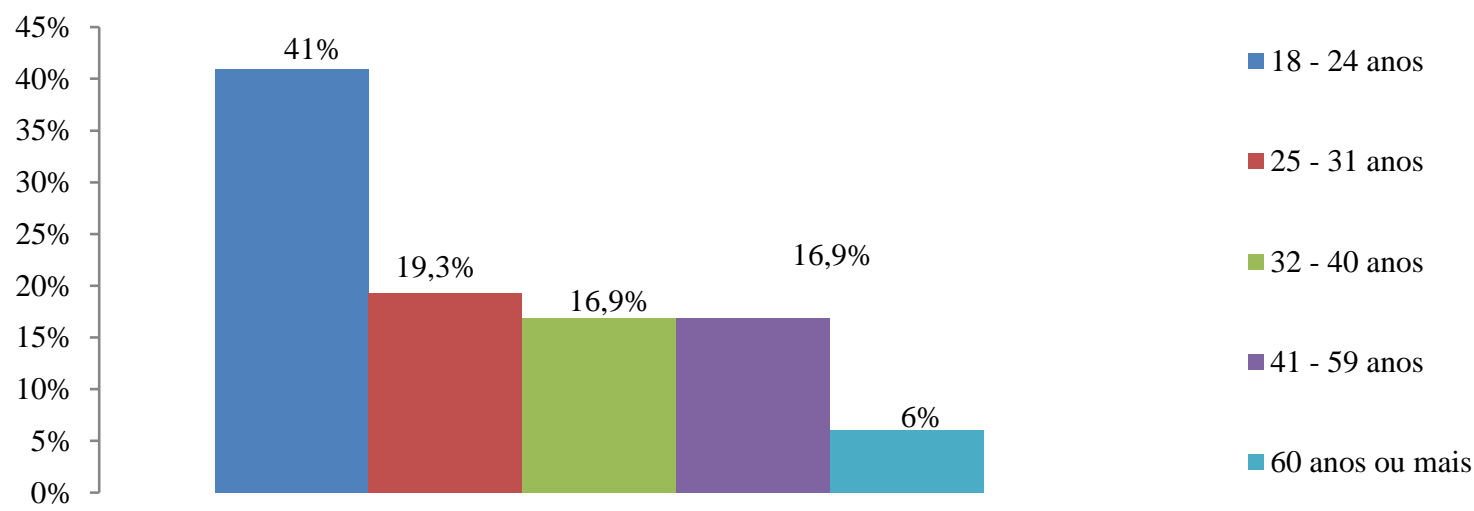

Gráfico 9. Percentual de faixa etária dos entrevistados sobre síndrome dos braquicefálicos por questionário fechado online entre janeiro e junho de 2020. $(n=83)$.

Segundo a pesquisa apenas $36,1 \%$ se informaram sobre a doença pelo seu médico veterinário de eleição, 34,9\% afirmaram não saberem do que se trata, $18,1 \%$ se informaram pela Internet, $7,2 \%$ se informaram por um amigo ou familiar e 3,6\% pelas Revistas ou Jornais. Significando que apenas 36,1\% dos tutores entrevistados se informaram sobre a doença através de fontes seguras (Gráfico 10). A maioria das informações disponíveis na internet a respeito da área da saúde, possuem informações insuficientes ou errôneas, principalmente a respeito dos tratamentos existentes para as diversas patologias (Moretti et al., 2012). A busca por essas informações infundadas se dá por estarmos inseridos na era digital, onde buscamos respostas imediatas aos nossos problemas, gerando ondas de notícias falsas, o que se torna muito prejudicial para a saúde e bem-estar do animal. Contudo se investíssemos em nos tornar veículos de informações seguras, esses índices poderiam ser melhores.

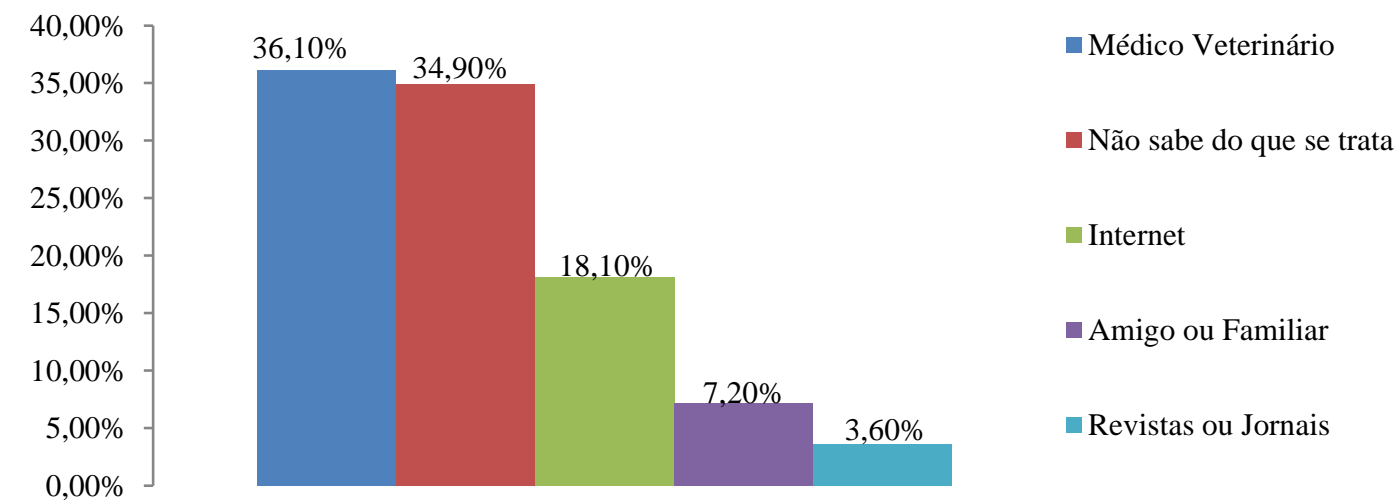

Gráfico 10. Percentual de entrevistados em questionário online fechado sobre síndrome braquicefálica que responderam como tomaram conhecimento da mesma de janeiro a junho de $2020(n=83)$. 


\section{Conclusão}

A maioria dos tutores já tinha ouvido falar a respeito da Síndrome das Vias Aéreas dos Cães Braquicefálicos, mas não sabiam informar se seu animal possuía ou não a mesma, apesar de apresentarem um ou mais sinais clínicos recorrentes característicos da mesma.

\section{Referências bibliográficas}

Almeida, P. G. (2012). Colapso traqueal em cães. Universidade Federal do Rio Grande do Sul.

Carvalho, A. D., Araújo, A. C. P., Gaiga, L. H., \& Cavalcante, R. L. (2010). Síndrome braquicefálicaestenose de narinas em cão. Acta Scientiae Veterinariae, 38(1), 69-72. DOI: https://doi.org/10.22456/1679-9216.16545

Colville, T. (2011). Anatomia e fisiologia clínica para medicina veterinária. Elsevier Brasil.

Crivellentin, L. Z., \& Borin-Crivelletin, S. (2015). Casos de rotina em medicina veterinária de pequenos animais. In MedVet. MedVet.

Jericó, M. M., Kogika, M. M., \& Andrade Neto, J. P. (2015). Tratado de medicina interna de cães e gatos. Guanabara Koogan.

Liu, N., Adams, V. J., Kalmar, L., Ladlow, J. F., \& Sargan, D. R. (2016). Whole-body barometric plethysmography characterizes upper airway obstruction in 3 brachycephalic breeds of dogs. Journal of Veterinary Internal Medicine, 30(3), 853-865. DOI: https://doi.org/10.1111/jvim.13933

Mendes Junior, A. F., Silva, G., Silva, V. M., Silva, S. C. G., Braga, S. P., Leite, C. R., Soares, A. M. B., \& Almosny, N. R. P. (2019). Hemogasometria arterial pré e pós-rinoplastia em cães braquicefálicos portadores de estenose de narina. Arquivo Brasileiro de Medicina Veterinária e Zootecnia, 71(1), 137-142. DOI: https://doi.org/10.1590/1678-4162-10203

Moraes, P., Büerger, C. P., \& Isola, J. G. M. P. (2012). Síndrome aérea dos braquicefálicos-estenose de narina em cão: Relato de caso. Revista Científica Eletrônica de Medicina Veterinária, 18(1), 1-8.

Moretti, F. A., Oliveira, V. E., \& Silva, E. M. K. (2012). Acesso a informações de saúde na internet: uma questão de saúde pública? Revista Da Associação Médica Brasileira, 58(6), 650-658. DOI: https://doi.org/10.1016/s2255-4823(12)70267-9

Oechtering, G. (2010). Síndrome braquicefálica: novas informações sobre uma antiga doença congênita. Veterinary Focus, 20(2), 10-18.

Stockard, C. R. (1941). The genetic and endocrine basis for differences in form and behaviour as elucidated by studies of contrasted pure-line dog breeds and their hybrids. American Anatomy Memoir, 19, 314-315. DOI: https://doi.org/10.1016/S0096-6347(42)90496-4

Tangner, C. H., \& Hobson, H. P. (1982). A retrospective study of 20 surgically managed cases of collapsed trachea. Veterinary Surgery, 11(4), 146-149. DOI: https://doi.org/10.1111/j.1532950X.1982.tb00691.x

Teichmann, C., Pereira, M. A. M., \& Reimann, P. (2012). Alterações anatômicas em cães com síndrome braquicefálica. UNICRUZ.

Histórico do artigo:

Recebido: 17 de dezembro de 2020.

Aprovado: 15 de janeiro de 2021.
Licenciamento: Este artigo é publicado na modalidade Acesso Aberto sob a licença Creative Commons Atribuição 4.0 (CC-BY 4.0), a qual permite uso irrestrito, distribuição, reprodução em qualquer meio, desde que o autor e a fonte sejam devidamente creditados. 